\title{
The Significance of Roll Calls in Voting Bodies: A Model and Statistical Estimation
}

\section{Citation}

King, Gary. 1986. The significance of roll calls in voting bodies: A model and statistical estimation. Social Science Research 15(2): 135-152.

\section{Published Version}

doi:10.1016/0049-089X(86)90012-8

\section{Permanent link}

http://nrs.harvard.edu/urn-3:HUL.InstRepos:4320279

\section{Terms of Use}

This article was downloaded from Harvard University's DASH repository, and is made available under the terms and conditions applicable to Other Posted Material, as set forth at http:// nrs.harvard.edu/urn-3:HUL.InstRepos:dash.current.terms-of-use\#LAA

\section{Share Your Story}

The Harvard community has made this article openly available.

Please share how this access benefits you. Submit a story.

\section{Accessibility}




\title{
The Significance of Roll Calls in Voting Bodies: A Model and Statistical Estimation
}

\author{
GARY KING \\ Department of Politics, New York University
}

In the long history of legislative roll call analyses, there continues to exist a particularly troubling problem: There is no satisfactory method for measuring the relative importance or significance of individual roll calls. A measure of roll call significance would be intersting in and of itself, but many have realized that it could also substantially improve empirical research. The consequence of this situation is that hundreds of researchers risk heteroskedastic disturbances (resulting in inefficient estimates and biased standard errors and test statistics), are unable to appropriately choose the roll calls most suited to their theory (resulting in analyses that may not correctly test their theory), and often use methods that create more problems than they solve (resulting in selection bias, unrealistic weighting schemes, or relatively subjective measures). This article introduces a new method designed to meet these problems. Based on an application of BoxTiao intervention analysis, the method extracts from observed voting participation scores the "revealed preferences" of legislators as a measure of roll call significance. Applying this method to roll calls from the U.S. Senate demonstrates the success of the method and suggests its utility in applied research. 1986 Academic Press, Inc.

In the numerous recent studies of voting behavior in legislatures, the question of deciding upon the relative significance of roll calls remains a persistent and unsolved methodological problem. (Riker, 1959: 377)

Since 1959, common research practices and widely used conventions have flourished, but obvious and unmeasured variations in the significance of legislative roll calls continue to be a nagging concern. ${ }^{1}$ More than a

Send requests for reprints to Gary King, Department of Politics, New York University, 25 Waverly Place, New York, NY 10003. An earlier version of this article was presented at the annual Political Science Methodology Society conference, Berkeley, California, 2528 July 1985. I appreciate the helpful comments from the participants at that meeting, particularly those of Christopher Achen and Nathaniel Beck. Thanks also to my colleagues at New York University, especially Steven Brams and Paul Zarowin. I also appreciate the comments from Mitchell Duneier, George Edwards, Arthur Goldberger, Barbara Hinckley, ' Charles Pearson, the editors, and the anonymous referees.

1 Although I develop a statistical model, my use of the term "significance" is not meant to refer to "statistical significance" or to have any statistical connotations. For a definition 
quarter of a century later, researchers continue to note that, "there is no objective way to determine the most important vote" (Edwards, 1985: 673). Because of the unusual quality and extent of the data-on the floor and in committees of the U.S. Congress, in some state legislatures, and in other voting bodies around the world-it is also an important methodological problem for social science research.

A measure of the significance of roll calls could substantially improve empirical research. For example, Matthews and Stimson (1975) argued that, as designed, their simulation "model applied only to a subset, the low-stakes, routine decisions" (see also Cherryholmes and Shapiro, 1969). For Asher (1973: 8), "it is the non-routine, often controversial, rancorous issue that is often of primary interest" (see also Kingdon, 1981). Most legislative theories apply best to particular types of roll calls-either the most significant, the most routine, or the most representative. However, with no generally accepted method of estimating the significance of roll calls in voting bodies, scholars routinely use all roll calls for selected years to conduct their analyses. The consequence of not discriminating among types of roll calls can be serious. For example, since there is likely to be more variance (error) in predictions for roll calls that are theoretically inappropriate than for those that are appropriate, these model disturbances are surely heteroskedastic (i.e., have nonconstant variances). This results in inefficient estimates and biased standard errors and test statistics. If the significance of roll calls were known and utilized, these problems could be avoided. Furthermore, this additional information could be used to improve existing substantive theory. Interaction terms or separate equations could be used to model those independent variables which are likely to be most powerful among less significant roll calls and others which are more useful among more significant roll calls. Variations in roll call significance across groups (party, regional, and ideological factions) could also provide an added dimension to legislative analysis.

The most fully developed and justified method of assigning significance scores to individual roll calls is by William H. Riker (1959). Professor Riker proposes deriving a roll call significance score by combining the margin (of victory or defeat) with the number of representatives who participate in the vote. The thought was that margin would measure "the degree to which [legislators] contest [a roll call] outcome" (1959: 379).

of "roll call significance," I have adopted Riker's (1959: 378) "distinction between the significance of a roll call, a judgment made at the time a roll call occurs, and the importance of a roll call, a judgment made at some time after it occurs." Riker argues that the judgment of roll call importance "both of the individual scholar and of any conceivable panel of outside experts is suspect. The only remaining persons available to evaluate the significance of roll calls are the members of the legislature themselves." Thus, instead of using a complex series of coding rules to ascertain a priori importance, concentration is on the behavior of legislators to estimate realized importance, what is called here "roll call significance." 
Participation was also seen as a measure of effort; the more significant the roll call, the more participants there would be. By assigning values to a table (rows indicating levels of participation and columns indicating closeness of margin) he derives a unique score for each combination of participation and margin.

This effort deserves a lot of credit for being the first and still the most systematic and sustained treatment of the topic. However, three relevant criticisms can be applied. First, Yohe (1968) does not propose to change the essence of Riker's argument, but he does note several biases in, and makes a number of useful corrections to, Riker's method.

Second, the method assumes that a narrow margin is the mark of an important roll call. While this may sometimes be true, I would argue that most often it is not. Consider five arguments: (a) A roll call with a narrow margin is not necessarily one which is significant. Imagine, for example, a roll call which has neither meaning nor significance for any legislator. In that extreme case, it is likely that votes would be cast randomly-resulting, on average, in a 50-50\% tie and the narrowest of margins. In a similar case of very low significance, complete cue taking is likely to result in the margin reflecting the party division in the legislature-still a very narrow margin. On much more significant roll calls, the margin might turn out to be small or large depending upon the distribution of preferences. Thus, margin seems not to be a very good direct measure of roll call significance. (b) Although heightened controversy seems likely to be related to importance-since controversy implies that a roll call is significant to at least some legislators-a close margin is unlikely to reflect controversy. In the case of an insignificant roll call with a narrow margin, the issue should also be noncontroversial. It seems, therefore, that margin would also make a poor indirect measure of significance. (c) Another possibility for using margin is as an indirect measure of significance through visibility. It could be argued that since elected officials value publicity, a visible roll call would be a significant one. The problem here is that a close margin does not appear to guarantee visibility. A unanimous censure of a colleague, for example, is likely to have very high visibility. Thus, the margin of victory is quite a poor direct and indirect measure of roll call significance. (d) Furthermore, margin and participation are empirically unrelated. For example, in the 200 roll calls analyzed below, the bivariate correlation between participation and margin is only 0.015 . This makes the idea that the two variables represent one underlying dimension dubious at best. (e) Finally, since most legislative bodies are characterized by full information and strategic voting, the dichotomous outcome of the roll call (win/lose) is probably of more importance than the margin. Votes over and above the margin many times reflect short-run constituency and other pressures. ${ }^{2}$

${ }^{2}$ Some studies omit roll calls on the basis of the margin of victory (see Footnote 3). 
Finally, Riker's method seeks to "determine" rather than "estimate" roll call significance. This is a crucial distinction; for only with statistical estimation of intersting formal models can we make reliable probabilistic inferences and empirically based conclusions. The statistical model which follows, therefore, builds on Riker's useful model but concentrates more on estimation. ${ }^{3}$

In separate sections, the remainder of this paper (1) builds a model of roll call significance, (2) identifies the appropriate methods of measuring the variables and estimating the parameters of this model, and (3) estimates and evaluates the model based on 6 months of roll calls from the United States Senate.

\section{A MODEL OF ROLL CALL SIGNIFICANCE}

By dropping margin (of victory or defeat) from Riker's (1959) measure, only the number of members participating in a roll call remains. This is a plausible measure of significance, consistent with Riker's, which allows the legislators' behavior to define the significance of roll calls (for an application, see King, 1986a). If a roll call is more important, it is assumed that more will participate. If it is less significant, then the constant pressures of constituents and others will reduce participation. Since roll call significance is unobservable, or is at least very difficult to measure (see Footnote 1), we extract an indicator from a phenomenon which is easier to observe-the participatory behavior of the legislators. Significance, then, is evaluated by the members of the legislature, and it is a measure of how important the legislators themselves see each roll call.

These procedures are not only irrelevant to their stated purpose, but they can result in serious selection bias if the vote margin were correlated with the dependent variable. An example of a dependent variable which may cause problems in this case is the degree of partisanship.

${ }^{3}$ At least seven more limited procedures have been applied to or proposed for the problem of variations in roll call significance. None are as promising, as general, or as justifiable as Riker's method. (1) Turner (1951: 20, cf. Riker, 1959: 379) weights all roll calls equally and assumes only important roll calls make it to the floor. (2) Using interest group ratings of senators and representatives has the "advantage that it does not require a researcher to make any judgments about what roll calls to include in the analysis. ... In effect, the interest groups do it for the researcher" (Poole and Daniels, 1985: 398). (3) Others weight all roll calls equally and assume that all or a vast majority are routine decisions (see Matthews and Stimpson, 1975). (4) Still others eliminate all unanimous or nearly unanimous roll calls (usually those with a margin more lopsided than 90-10\%). (5) Sigelman (1979) introduced Congressional Quarterly's (CQ's) annual list of "Key Votes" as a measure of roll call importance; Key Votes are 14 to 17 roll calls in the House and Senate each annually selected by the CQ editors; see LeLoup and Shull (1980) for criticisms of this relatively subjective measure. (6) Some personally select a small number of significant roll calls based on interviews or a close reading of the congressional process; this amounts to replicating the Congressional Quarterly method, but perhaps with different or more systematic selection rules (see Kingdon, 1981). (7) A final "method" is to drop all roll calls which do not fit a Guttman or other issue or ideological scale. 
A moment's reflection, however, indicates at least two major problems with raw participation as a measure of significance. First, participation is a function of other factors that are unrelated to roll call significance. Examples of these are procedural variables such as the day of the week (as participation on Monday and Friday is probably lower than on Tuesday, Wednesday, and Thursday), proximity to election day, the institution of electronic voting, vacant seats, and illnesses.

Second, if a highly significant roll call occurs, and members rush to Washington to cast their votes, participation will increase. However, since legislators have an electoral incentive to keep their personal participation rates as high as possible, roll call participation is likely to remain artificially high for several more votes even if only insignificant issues are considered (Riker, 1959: 380). Thus, raw participation levels would overestimate the significance of unimportant votes which succeed important ones.

We need, therefore, a method of controlling for the influence of the significance of previous roll calls on current participation levels. At the same time, we need to control for the effect of procedural variables on participation. These requirements can be met by a form of a Box and Tiao (1975) "intervention model."

The Roll Call Significance Model

where

$$
n_{t}=\alpha+X_{t} \beta+\theta(B) s_{t}
$$

$n_{t}=$ the number of legislators voting on roll call $t(t=1$, ..., T),

$\alpha=$ an intercept term

$\beta=$ a parameter vector representing the influence of $X_{t}$.

$X_{t}=$ a vector of observed procedural variables that influence the number of legislators participating in roll call $t$.

$$
\theta(B)=\begin{aligned}
& \left(1-\theta_{1} B-\theta_{2} B^{2}-\cdots-\theta_{q} B^{q}\right), \text { a } q^{\text {th }} \text {-order } \\
& \text { polynomial in the back shift operator } B \text { where }
\end{aligned}
$$

$B^{k} s_{t}=s_{t-k}$, for $k=1, \ldots, q$,

$\beta_{1}, \ldots, \beta_{q}=$ parameters representing the influence of previous values of $s\left(s_{t-1}, \ldots, s_{t-q}\right)$ on the current value of $n_{t}$, (these are hypothesized to be negative),

$q=$ the number of roll calls for which a shock to $s_{t}$ continues to be felt,

$s_{t}=n_{t}-\alpha-X_{t} \beta+\left(\theta_{1} s_{t-1}+\theta_{2} s_{t-2}+\cdots+\theta_{q} s_{t-q}\right)$, roll call significance, unobserved due to $\alpha, \beta$, and $\theta_{1}$, $\ldots, \theta_{q}$ (the last term in parentheses is calculated by multiplying $s_{t}$ by the right-hand side of $\theta(B)$ ).

In a sense, the last line in this model, with $s_{t}$ on the left-hand side, 
is the equation of interest; thus, the first line is the directly estimable reduced form equation. In either case, $s_{t}$ can be considered a vector of unobserved parameters measuring the significance of each roll call to the members of the voting body under study. It is equal to participation $\left(n_{t}\right)$, purged of the effects of the procedural variables $\left(X_{t}\right)$ and of previous random shocks to significance $\left(s_{t-1}, s_{t-2}, \ldots, s_{t-q}\right)$.

A moving ayerage process $\left(\theta(B) s_{t}\right.$ in the model) best represents these shocks, since the shocks are hypothesized to change the level of significance of the roll call and, only in turn, to influence participation. The president, the party leaders, or random or exogenous political or economic circumstances causes an important roll call to be brought to the floor for a vote. Legislators then come to Washington, DC to participate in this substantially more significant roll call. The shock propagates for only a few more roll calls as inertia, convenience, and electoral incentive keep the participation level high, even if these succeeding roll calls are not as significant. The model assigns $q$ (the order of the moving average process) as the number of roll calls for which participation remains artificially high. Before turning to the data used in estimating this model and the specific choice for $X_{t}$ and $q$, a discussion of three unresolved issues is warranted.

First, this model does not separate roll call significance from random error. It makes the strictly incorrect assumption that there is no error. In addition to a close reading of the scholarly literature and the congressional process, two reasons make this unlikely to cause a problem. In one, $s_{t}$ should closely resemble random error-a series of random shocks with no lags. In the other, the statistical estimation will produce an unbiased estimate of $s_{t}$. Any error would be distributed randomly and would therefore not systematically bias the estimator.

Second, most of the statistical literature on time series models assumes that there are equal time intervals. In the case of roll calls, this is not usually the case. The point to remember, however, is that physical time is less relevant in this case than psychological time, and the latter can be characterized by equal intervals. More importantly, alternative specifications which explicitly model physical time were tried, but they added little to this model.

A third potential problem is that some legislators may abstain in order to escape from expressing a preference. Four arguments help to refute this assertion. First,

The only reasonable way to explain such behavior is to say that the abstainers value the effect of their abstention more than the effect of their vote. And this is another way of saying that they do not value their vote on this issue as highly as the effects of abstention. One cannot evade the conclusion, therefore, that the vote in itself is not of the highest significance. (Riker, 1959: 381)

Second, when interest groups (such as the Americans for Democratic Action), constituents, or party leaders maintain an attitude such that 
" 'He who is not with me is against me," " legislators "are less likely to abstain" (Fiorina, 1974: 79). Third, some interest groups and organizations such as Congressional Quarterly do regular polls of abstainers in order to determine their unstated preferences. These polls are expected and are regularly answered by members of congress. They are then published. Thus, in the U.S. Congress, abstention is quite a poor way to evade making a decision. Finally, abstention is not popular among constituents and is often the basis of challengers' congressional compaigns. Since abstention seems to be more unpopular when it occurs on significant votes, participation is even more likely to be an accurate measure of roll call significance.

Thus, this roll call significance model produces a "revealed preterence" measure: The assessment of the significance of each roll call is revealed by the legislators through their behavior. In economics and in other areas of social science, scholars have shown that revealed preference measures are universally superior to opinion polls, expert judgments, and any other measure. For example, to estimate expected inflation, economists prefer to use the prices of treasury bills rather than to ask experts for their expectation of price increases (Fama and Gibbons, 1984). In a similar manner, the model developed here uses a realized or revealed preference estimate for a measure of roll call significance.

\section{ESTIMATING ROLL CALL SIGNIFICANCE}

The number of legislators participating, $n_{t}$, is measured with all 200 roll calls in the United States Senate occurring during the first 6 months of 1980 . There was no compelling reason to select this period rather than any other, and there is no reason to believe that the relationships reported here differ from those in the rest of the series. I believe that the results also apply to many other voting bodies around the world, but this verdict should await the application of this model to these other legislatures.

To estimate this model, only the precise definition of the procedural variables $\left(X_{t}\right)$ and the number of roll calls for which a shock to significance continues to be felt $(q)$ need to be specified.

The procedural variables, $X_{t}$, are measured in a variety of ways and methods. Week, was coded as 1 if roll call $t$ occurred on Friday through Monday and 0 if Tuesday through Thursday. To test the assumption of equal psychological time intervals, and to control for unequal intervals if necessary, Lastvote, was coded as the number of days between the roll call at time $t$ and the roll call at time $t-1 .{ }^{4}$ For testing purposes, the margin (of victory or defeat), whether the president takes a position on the roll call, the policy area of the roll call, and measures of intraparty

${ }^{4}$ Congressional Quarterly (1980: 24C) reported that 20 Republican Senators and three Democratic Senators were "absent for a day or more in 1980 because they were sick or because of illness or death in their families." However, since most were only absent for very short periods, this is unlikely to influence the results. 
cohesion and interparty competition were also included. However, preliminary analyses indicated that the only variable that appreciably influenced participation was Week .

Based on media reports and the Congressional Record during these 6 months, and on more general substantive considerations, a plausible guess for $q$ is that after a particularly significant roll call, representatives would stay in Washington and on the floor for three to seven additional roll calls. Empirical experimentation led to a value for $q$ of four roll calls. Thus, according to this model, senatorial voting participation remains artificially high on average for four roll calls after being stimulated by a roll call with a particularly high significance level. ${ }^{5}$

The parameters of this model are estimated simultaneously as a Box and Tiao (1975) intervention model. ${ }^{6}$

\section{EMPIRICAL ANALYSES}

Table 1 provides estimates of the version of this model chosen for extended presentation. Note first that the $Q$ statistic (Ljung and Box, 1978) indicates that the residual from this estimation are not significantly different from white noise as a set, as required for a good estimate of roll call significance. The " $R$ " "statistic is conceptually analogous, although not algebraically equivalent, to that in ordinary regression analysis. It indicates that in this sample the procedural variables and the effects of the significance of previous roll calls "explained" $37.8 \%$ of the variance. The remaining variance $(62.2 \%)$ is attributed to roll call significance. ${ }^{7}$

The parameter estimate of the Week, variable indicates that after taking into account previous shocks to roll call significance, holding a roll call on a Monday or a Friday depresses participation by about six senators.

s Across various models with different specifications of both $X_{t}$ and $q$, parameter estimates were quite stable. Autoregressive and mixed autoregressive-integrated-moving-average (ARIMA) models also were experimented with, but moving average processes were substantively and empirically most plausible. Furthermore, the various estimates of roll call significance correlated very highly across models (usually between .98 and 1.00 , but never lower than .92). The model chosen for presentation ( $q=4$ and $X \in$ Week $_{t}$ ) represents the others well, but it also appears to most closely represent reality and to best estimate roll call significance.

5 At first glance, some might believe that this model could be estimated by first running a regression of $n_{t}$ on $X_{t}$ and calculating the residuals. These residuals could then be purged further by modeling them as a univariate fourth-order moving average process and calculating the new residuals. These new residuals would be our estimate of significance. The problem with this "stepwise" method is that the random shocks representing previous values of roll call significance seem likely to be correlated with some of the procedural variables (e.g., highly significant roll calls would be less likely to be held on a Friday or Monday). The result would be biased estimates (Achen, 1978; Goldberger, 1961).

7 This is a reasonable proportion, since it does suggest that the model explains a fair portion but still leaves the residuals (i.e., $\hat{s}_{t}$ ) with an interesting amount of variation. As is nearly always the case (see King, in 1986b), the goal is not to get an $R^{2}$ of 1.0 . 
TABLE 1

Statistical Estimates of the Roll Call Significance Model ${ }^{a}$

\begin{tabular}{lcccc}
\hline $\begin{array}{l}\text { Parameter } \\
\text { to be } \\
\text { estimated }\end{array}$ & Variable & Estimate & $\begin{array}{c}\text { Standard } \\
\text { error }\end{array}$ & Prob (estimate $\geqslant 0$ ) \\
\hline$\alpha$ & Constant & 90.391 & 0.758 & \\
$\beta$ & Week & -6.070 & 1.212 & $<0.001$ \\
$\theta_{1}$ & $s,-1$ & -0.580 & 0.070 & $<0.001$ \\
$\theta_{2}$ & $s, 2$ & -0.408 & 0.079 & $<0.001$ \\
$\theta_{3}$ & $s,-3$ & -0.260 & 0.079 & 0.001 \\
$\theta_{4}$ & $s,-4$ & -0.125 & 0.071 & 0.039 \\
\hline
\end{tabular}

Note. Standard error of the residuals $=4.376$; proportionate reduction in error (" $R$ ") $=0.378 ; Q\left(\sim\right.$ a $\chi^{2}$ variable, $\left.22 d f\right)=18.600$; Prob (the residuals are white noise $\left.\mid Q\right)=$ 0.669 .

a The model is invertible.

The parameter estimates on the previous random shocks (the moving average process) very plausibly indicate that a change in significance occurring for one roll call would have about $58 \%$ reverberation during the next period, $41 \%$ during the next, $26 \%$ in the next, and $13 \%$ in the fourth. ${ }^{8}$ The standard errors are all very small, indicating very precise estimates, and the marginal probabilities (in the last column) indicate that if another random sample of roll calls were taken, all of the parameters would almost surely remain different from zero and retain the same sign.

From these plausible coefficients, the estimate of the significance of each roll call to the members of the U.S. senate was generated. Although describing all 200 roll calls in this paper is not feasible, Tables 2 and 3 provide estimated significance scores $\left(\hat{s}_{t}\right)$, Congressional Quarterly roll call numbers (for reference), and substantive descriptions for the 10 most and 10 least significant roll calls-as determined by the legislators' actions themselves, as interpreted by the roll call significance model, and as estimated in Table $1 .{ }^{9}$

Votes chosen as among the most highly significant to the senators include 10 apparently important issues (Table 2). All were of relatively high salience to the legislators and high visibility to the public. In general, the issues selected as least important (Table 3) were considerably more

${ }^{8}$ These figures are a direct interpretation of the model estimates of $\theta_{2}, \theta_{2}, \theta_{3}$, and $\theta_{4}$ appearing in Table 1. When other lags of $s_{t}$ were included in the model they did not appreciable influence $s$, or the other estimates, but they continued to be plausible, dropping at about the same rate as the first four.

${ }^{9}$ Interpreting these tables is relatively easy, but it is crucial to remember that any consideration of the substance of each bill is an evaluation of roll call "importance" rather than "significance." This is necessary, however, to help evaluate the utility of the model. As such, the discussion which follows is relatively subjective compared to the results in the tables. 
TABLE 2

The Ten Most Significant Senate Roll Calls

$\left(\hat{s}_{t}\right)$

Significance

CQ No. score Title and description

11.84

S 2352 Council on Wage and Price Stability Extension.

Reduce authorizations from $\$ 13.7$ million in fiscal 1980 and $\$ 25$ million in fiscal 1981 to $\$ 9.5$ and $\$ 9.8$ million, respectively. There was substantial debate and public attention. This was the first of 10 votes attempting to amend the bill. The final roll call was pro forma, since the real decision had been made on this vote (p. 305). Adopted, $n,=80,6 / 2 / 80$.

Motion to invoke cloture (thus limiting debate) on the joint resolution to transfer $\$ 13.3$ million from the Airforce System in order to provide enough funds to register 19- and 20-year-old males, beginning in 1980 in case a military draft became necessary in the future. President Carter, changing his position in response to the Soviet invasion of Afghanistan, already had the authority and needed only these funds for implementation. The plan was very controversial: "all of Carter's

Amendment allowing Justice Department suits only when the Attorney General has substantial evidence that a person is being subjected to egregious or flagrant conditions. This was fourth of eight consecutive roll calls on the same topic, but all were on different points. The language in this amendment ("egregious or flagrant conditions") struck at the heart of this plan. Rejected, $n_{t}=90,2 / 28 / 80$ (see HR 10, below).

H J Res 554 Fiscal 1980 Federal Trade Commission Appropriation.

Motion to table (kill) the Weiker, R-Conn., amendment to bar federal assistance for the Chrysler Corporation until Chrysler had secured nonfederal assistance of at least $\$ 1.43$ billion. First of two consecutive votes on the FTC; the second was not about Chrysler. Motion agreed to, $n_{t}=93,6 / 3 / 80$

$S$ Con Res 86 Fiscal 1981 Budget Targets.

Motion to table (kill) the Cohen, R-Maine, amendment to reduce fiscal 1981 budget authority and outlays of water projects by $\$ 500$ million. This was 7 th of 41 votes on budget targets (with 2 intervening votes), but it was the only one on water projects. Motion agreed to, $n_{t}=94,5 / 7 / 80$. 
7.72 H Con Res 272 Release of Soviet Dissident Andrei Sakharov.

Adoption of concurrent resolution to express (1) the sense of congress that Nobel laureate Andrei Sakharov, who condemned the Soviet invasion of Afghanistan, be released from internal exile and (2) to support President Carter's economic sanctions against the Soviet Union and (3) refusal of U.S. participation in the 1980 Summer Olympics in Moscow. Adopted, $n_{t}=91,2 / 19 / 80$.

Adoption of the resolution urging the Moscow Summer Olympic Games be moved, canceled, or boycotted, as a protest against the December 1979 invasion of Afghanistan. Adopted, $n_{r}=92,1 / 29 / 84$.

$53 \quad$ HR 4612 Unemployment Compensation.

Amendment to require, rather than permit, states to exclude an employee's contribution to his pension in deducting the amount of pension payments from unemployment benefits. First vote of only two on this topic. Congress eased a 1976 law requiring states to reduce weekly unemployment compensation benefits to retirees by the amount received from any private or public pension. Rejected, $n_{1}=92,3 / 4 / 80$.

HR 10 Rights of the Institutionalized.

Adoption of the conference report on the bill to authorize the Justice Department to file lawsuits against states to protect the rights of those confined in state institutions. The final action was by voice vote. With one intervening vote there were six votes on the same issue just prior to this one. This is the second vote on the same issue in the top 10 (see CQ 47); the method "selected" each of the two votes from different series of votes on the issue. Adopted, $n_{t}=93$, $5 / 6 / 80$.

HR 5168 Military Personnel Management Extension.

Motion to table (kill) the Warner, R-Va., amendment to the Armstrong amendment to increase military pay by $3.4 \%$.

First of two on the same topic. The issue was decided de facto here, since on the next vote (and a later voice vote) the bill passed as a formality. This was a key test of the Nunn-Warner Military benefits package which contained seven major military programs. Motion rejected, $n_{t}=87,2 / 4 / 80$.

Note. Source: Table 1. Roll call descriptions were all paraphrased or quoted from the Congressional Quarterly Almanac (1980). Page references are given only when quoting from Congressional Quarterly news descriptions. 
TABLE 3

The Ten Least Significant Senate Roll Calls

$\left(\hat{s}_{t}\right)$

Significance

CQ No. score

Title and description

$156-23.8$

HR 7471 Debt Limit Extension.

Passage of the bill to extend the public debt limit at its existing level of $\$ 879$ billion from May 30,1980 through June 5,1980 . This was a technical requirement to keep the government running while congressional leaders and the president mustered enough support to pass the annual extension. Passed, $n_{t}=57,5 / 30 / 80$.

H J Res. 545 Fiscal 1980 Food Stamp Supplemental Appropriation.

Adoption of the conference report on the joint resolution to provide a supplemental appropriation of a little less than asked for by the Senate previously for 1980 . It directs the Agriculture Department to proceed on the assumption that total spending for the year would be $\$ 9.191$ billion and to prohibit more spending. The day before there had been a series of more controversial, high-visibility roll calls. "With the way cleared for adoption of the emergency funding bill by adoption of the authorization measure (S 1309), both chambers adopted the conference report" (p. 415). Adopted, $n_{i}=74,5 / 15 / 80$.

$88-11.95 \quad$ H J Res 541 Emergency Fiscal 1980 Appropriations.

Passage of the joint resolution to transfer $\$ 7.6$ million to the Federal Trade Commission for May I, 1980 to May 31 , 1980, from the State Department's contributions to international organizations. This was a temporary measure in order to keep the FTC's “doors from closing." The $\$ 7.6$ million was later restored to the State Department (p. 147). Passed, $n_{t}=81,5 / 1 / 80$.

$41-11.64 \quad$ HR 3757 Channel Islands National Park.

Passage of bill to establish 246,985-acre Channel Islands National Park on five islands off the southern California coast and to make technical changes to the National Parks and Recreation Act of 1978. Passed, $n_{t}=73,2 / 18 / 80$.

$52-10.12$ S 1725 Low-Income Home Weatherization.

Passage of bill to authorize $\$ 2.2$ billion in fiscal 1981-1983 to assist low-income persons to "weatherize" their homes to conserve energy. It was perceived as an energy issue rather than social welfare and was not the focus of much attention. Later, "the legislation got bogged down in a committee jurisdiction dispute in the House and never cleared" (p. 462). Passed, $n_{t}=80,2 / 28 / 80$. 
HR 7428 Oil Import Fee/Debt Limit.

Passage, over the president's veto the day before, of the existing debt limit of $\$ 879$ billion and to disapprove the $\$ 4.62$ fee per barrel of imported oil that President Carter imposed effective March 15. Required and received two-thirds vote. This was a high-visibility vote which was never taken seriously by most members of congress. "From the beginning the opposition movement attracted members from opposite ends of the political spectrum." Although Carter, June 4, had appealed to legislators to "stand up and take the political heat by making tough decisions," "earlier votes left no doubt that the veto would be overridden" (p. 273). This was probably important to Carter, but not to the Senate. Passed, $n_{t}=78,6 / 6 / 80$.

\section{$94-8.85 \quad S$ Con Res 86 Fiscal Budget Targets.}

Motion to table (kill) the Thurmond, R-SC, amendment to cut $\$ 800$ million in budget authority and $\$ 400$ million in outlays from public service jobs in fiscal 1981 and add the funds to veterans' programs. Most changes here were technical and not controversial. Motion agreed to, $n_{t}=83,5 / 6 / 80$.

Amendment to allow payment of larger disability benefits to workers whose previous monthly incomes had averaged between $\$ 600$ and $\$ 1000$ than had been allowed by the Finance Committee bill. "Through the use of a complicated formula, Javits' amendment would have brought the level of reductions in benefits to all other workers, with the exception of the very poorest" (pp. 436-7). Seventh of 10 on the same bill. One of the 10 was in the top $25 \%$ of important roll calls. Amendment rejected, $n_{t}=85,1 / 31 / 80$.

S 1309 Food Stamps.

Motion to recommit the bill to conference with instructions to the Senate conferees that they insist on the deletion of House amendments establishing an income deduction for employment-related dependent-care expenses, expanding the deduction for medical expenses, and affecting the annual adjustment of income deductions and food stamp benefits. The vote following this one, which approved the conference report, was more important, ranking 105 of the 200 roll calls analyzed. Rejected, $n_{r}=90,5 / 14 / 80$.

S 2337 Legal Services Corporation.

Motion to table (kill) the Helms, R-NC, amendment to prohibit Legal Services Corporation lawyers from handling food stamp cases. This issue was somewhat political, but it was the proposal of a very conservative Senator, which commanded little attention and had little chance of succeeding. Following this and two unrelated roll calls, six other more important Legal Services Corporation votes occurred. Motion agreed to, $n_{t}=86,6 / 12 / 80$.

Note. Source: Table 1. Roll call descriptions were all paraphrased or quoted from the Congressional Quarterly Almanac (1980). Page references are given only when quoting from Congressional Quarterly news descriptions. 
routine and trivial; these were characterized by very low visibility, controversy, and importance. In the remainder of this section, I present four rough ways to judge these assertions and a somewhat more detailed analysis of several of the bills.

As the first rough measure, consider the amount of discussion and news analysis of each roll call in the $1980 \mathrm{CQ}$ Almanac; because of the analytical presentation style, it is often difficult to separate out and objectively measure which words and articles exactly apply to each roll call. However, for the significant roll calls, it is clear that there was considerably more attention given than for the insignificant roll calls. Some of the issues addressed by the roll calls in the former group had detailed and separate articles or sections; the historical, policy, and political implications were often discussed. For some in the latter category, there was no discussion at all. For others, there was just a brief mention as part of a larger discussion of other topics.

As another rough measure, filibusters constitute a useful indicator of roll calls which are intensely significant to at least a minority of legislators. During the first 6 months of 1980, there were senate cloture votes (attempts to limit debate and thus break the filibuster) during four issues. None of these four were in the bottom 10, and two were in the top 10. The remaining two dealt with somewhat more narrow issues and were close behind the top 10 in significance scores. ${ }^{10}$

A third rough measure of the validity of this estimate of roll call significance is Congressional Quarterly's Key Votes (see Footnote 3). Since Key Votes are not intended to measure exactly what the measure here is geared for, we would not expect exactly the same results; however, there should be some correspondence. In fact, this is what we find. There were six issues during the first 6 months of 1980 that were identified by Congressional Quarterly's editors as Key. Three of these were in the top 10 of roll call significance (Table 2). Two of the remaining three were in the top $50 \%$ of significance scores. ${ }^{" 1}$

A final indication of the worth of this estimate of roll call significance $\left(\hat{s}_{t}\right)$ is to see how much of an improvement it is over the raw participation level $\left(n_{t}\right)$. A first indication of this was given with " $R^{2}$," a measure of the proportionate reduction in error from the null to the full model. A more precise indication can be found in Tables 2 and 3 for the 10 most and 10 least significant roll calls. The information in the tables indicates

${ }^{10}$ Of the 4 subject to a filibuster, the 2 in the top 10 were on the general issues of rights of the institutionalized and peacetime draft registration. The 2 falling just below the top 10 concerned Carter's nominee for the National Labor Relations Board (Lubbers) and an antitrust immunity bill for bottlers.

"Riker's method applied to these data leads to markedly different results. This is to be expected since the scale has such a low level of statistical reliability (due to the almost nonexistent correlation between margin and participation). 
that significance is correlated with participation, as is expected, since the former was based on the latter. However, the two time series are far from identical. For example, 6 of the 10 roll calls in the least significant group (Table 3 ) have participation levels higher than some roll calls in the high-significance group (Table 2). It is therefore quite worthwhile to expend the extra effort to purge participation of the procedural variables and of prior random shocks to significance, as has been done in the model presented and analyzed here.

Among the 10 roll calls identified by the model as most significant (Table 2), each was an apparently important issue. A vote to extend the authorization of the Council on Wage and Price Stability had a significance score of 11.84 , which means that, solely because of the significance of this roll call, nearly 12 more legislators participated than would have if this were an average roll call. During this time of unusually high levels of inflation, President Carter, in a message to congress, called the Council "essential;" it "played a vital role." Several senators "lashed out at" and felt considerable pressure from lobbyists, particularly the National Association of Manufacturers and the U.S. Chamber of Commerce (CQ, 1980: 305).

With a significance score just above 11 points, the funding of Draft Registration was a crucial issue during this session of congress. This vote ended a filibuster which lasted for 7 days. "[Public] consideration . . . lasted more than five months" (1980: 46). Another roll call was on the issue of Rights of the Institutionalized. This bill was "historic legislation authorizing the federal government to file suit against state institutions such as jails, mental hospitals and juvenile facilities" (1980: 383). It was a high-visibility issue which cut across several political lines (liberal/conservative, federal/state power, etc.).

What was called a Federal Trade Commission Appropriation $\left(\hat{s}_{t}=\right.$ 7.72), was really an amendment attempting to kill the renewal of Chrysler Corporation assistance for 1980 (the initial more visible, controversial, and important policy change occurred a year before). Another roll call was on Senate Continuing Resolution 86 which concerned water projects. "Carter first politicized this issue in 1978 when he vetoed 6 water projects." This popular bill which would put water projects in about $70 \%$ of congressional districts was also a target of attack and attention by Carter: "The water resources bill . . . is a bad bill. It's a wasteful bill. It's an inflationary bill." It is "shot through with textbook examples of wanton waste of American taxpayers' money" (1980: 209).

The next two votes in Table 2-on the release of Soviet Dissident Andrei Sakharov and on the Moscow Olympics-were not at all controversial. The first was unanimous, and the second had only four dissenting votes. However, both were quite visible, and were perceived to be bold 
moves (further confirming the notion that a wide margin does not necessarily indicate insignificance). ${ }^{12}$

On those issues where there were many consecutive roll calls, the most important one or two was usually given the highest significance score. For example, the roll call selected on the issue of draft registration funding was the first of 25 consecutive votes over 3 days. Of the 23 following this yote before final passage, "most [were] on procedural motions . . . introduced simply to consume time." The "battle actually was lost on the first vote of the debate when the Senate June 10 agreed to end the ... filibuster"' (1980: 46).

Sometimes the senate brought up the same issue on two or more occasions, each in a long series of roll calls. In cases such as this, the method tended to select one or more from each series as clearly the most important. For example, during the 6 months analyzed, there were two series of roll calls on the Rights of the Institutionalized, and only the most important one from each appeared in the top 10.

The model also chose plausible votes as the least significant (to the senators) among the 200 analyzed (see Table 3). At the top of the list was a 6-day extension of the debt limit. This was a very important issue, but a relatively unimportant roll call. The more important measure, extending the debt limit for 12 months, was passed after the 6-month period considered in this study. A pro forma approval of an already debated and decided Food Stamp appropriation was next. There was a temporary transfer of money between two government agencies which was required for purely technical reasons (and was later restored). The establishment of a small national park on islands off the coast of California and money to "weatherize" the homes of poor people were two other examples of roll calls receiving low significance scores.

One possible anomaly is an override of a presidential veto on an oil import fee bill. This was a vote of importance to President Carter, but it was never taken seriously by congress and was very quickly and overwhelmingly passed. Since the measure was intended to estimate the significance of roll calls to the legislators (and not necessarily to anyone else), this explanation seems plausible. Also at the bottom of the list are minor, routine, and technical amendments occurring during the debate of more important issues.

\section{CONCLUSIONS AND RECOMMENDATIONS}

The purpose of this paper was to build on Riker's (1959) model by providing an explicit statistical model which helped in estimating the degree to which each roll call in a voting body was significant to its members as evidenced by their actions. The roll call significance model

${ }^{12}$ For details on these and the other significant roll calls, see Table 2. 
was chosen based on theoretical understandings and on previous empirical evidence. The measure is essentially legislative participation purged of the effects of procedural variables and of the bias that occurs when unimportant roll calls follow important ones. This model was then estimated and presented in Table 1. Judging from the precise and plausible estimates of the parameters and of the interpretations of $\hat{s}_{t}$, the model appears to be a useful solution to the problem of variations in the significance of roll calls.

Although I have concentrated primarily on U.S. Congressional roll calls, this model, or a variation of it, should be as applicable in any voting body. To check, one should fit this model or an appropriate version of it and interpret the parameters and $\hat{s}_{t}$. The resulting estimates should be used either as weights in a weighted least squares (or other) statistical analysis, or as an explicit exogenous variable by itself or in interaction with other variables. This procedure could also be applied to mutually exclusive groups of legislators (such as Democrats and Republicans or southern Democrats and northern Republicans) to tap the relative importance of various issues to these different groups of legislators.

\section{REFERENCES}

Achen, C. H. (1978). On the Bias in Stepwise Least Squares, unpublished manuscript, University of California, Berkeley.

Asher, H. B. (1973). Freshman Representatives and The Learning of Voting Cues, Beverly Hills; Sage.

Box, G. E. P., and Jenkins, G. M. (1970). Time-Series Analysis: Forecasting and Control, Holden Day, San Francisco.

Box, G. E. P., and Tiao, G. C. (1975). "Intervention analysis with application to economic and environmental probelms," Journal of the American Statistical Association 70, 7079.

Cherryholmes, C. H., and Shapiro, M. J. (1969). Representatives and Roll Calls: A Computer Simulation of Voting in the Eighty-eighth Congress, Bobbs-Merrill, Indianapolis.

Clausen, A. R. (1973). How Congressmen Decide, St. Martin's, New York.

Congressional Quarterly (1980). Congressional Quarterly Almanac, Congressional Quarterly, Washington, DC.

Edwards, G. C. III (1985). "Measuring presidential success in congress: alternative approaches," Journal of Politics 47, (2, May), 667-685.

Fama, E. F., and Gibbons, M. R. (1984). "A comparison of inflation forecasts," Journal of Monetary Economics 13,(May), 327-348.

Fiorina, M. P. (1974). Representatives, Roll Calls, and Constituencies, Lexington Books, Lexington.

Goldberger, A. S. (1961). "Stepwise least squares: residual analysis and specification error," Journal of the American Statistical Association 56, 998-1000.

King, G. (1986a). "Political parties and foreign policy: a structuralist approach," Political Psychology, 7, in press.

King, G. (1986b). "How not to lie with statistics: avoiding common mistakes in quantitative political science," American Journal of Political Science, in press.

Kingdon, J. (1981). Congressmen's Voting Decisions (2nd ed.), Harper \& Row, New York.

LeLoup, L., and Shull, S. A. (1979). "Congress versus the executive: the two presidencies reconsidered," Social Science Quarterly, 59, (41, March), 704-719. 
Ljung, G. M., and Box, G. E. P. (1978). "On a measure of lack of fit in time series models," Biometrika 65, 297-304.

Matthews, D. and Stimson, J. A. (1975). Yeas and Nays: Normal Decision Making in the House of Representatives, Wiley, New York.

Poole, K. T., and Daniels, R. S. (1985). "Ideology, party, and voting in the U.S. Congress, 1959-1980," The American Political Science Review, 79(2, June), 334-358.

Riker, W. H. (1959). "A method for determining the significance of roll call votes in voting bodies," in Legislative Behavior: A Reader in Theory and Research, J. C. Wahlke and H. Eulau, Eds.), Free Press, Glencoe, IL.

Sigelman, L. (1979). "A reassessment of the two presidencies thesis," Journal of Politics 41, 1195-1205.

Turner, J. (1951). "Party and constituency: pressures on congress," Johns Hopkins Studies in Historical and Political Science 9, 1-190.

Yohe, W. P. (1968). "Riker's method for assessing the significance of roll call votes," Public Choice 4, (Spring), 59-66. 